\title{
Probing Trapped Ion Energies Via Ion-Molecule Reaction Kinetics: Fourier Transform Ion Cyclotron Resonance Mass Spectrometry
}

\author{
James E. Bruce and John R. Eyler \\ Department of Chemistry, University of Florida, Gainesville, Florida, USA
}

\begin{abstract}
The kinetic energy-dependent $\mathrm{Ar}^{+}+\mathrm{N}_{2}$ ion-molecule reaction has been used as a chemical "thermometer" to determine the kinetic energy of ions produced by electron ionization and trapped by using a Fourier transform ion cyclotron resonance (FTICR) mass spectrometer. The rate constant for this reaction obtained on the FTICR mass spectrometer was compared to previous work, which allowed a kinetic energy estimate to be made. In addition, the effects of varying parameters such as trapping voltage and pressure on ion kinetic energy were investigated. No evidence of the differing reactivity of higher energy electronic states of $\mathrm{Ar}^{+}$, such as ${ }^{2} \mathrm{P}_{1 / 2}$, was observed and the results of a model of this system are presented that support this observation. Pressure studies revealed that with an average of as few as 13 ion-molecule collisions, $\mathrm{Ar}^{+}$ions are collisionally relaxed to an extent unaffected by additional collisions. Based on recent variable temperature selected ion flow drift tube measurements, FTICR ion energies are estimated to be slightly above thermal. (J Am Soc Mass Spectrom 1992, 3, 727-733)
\end{abstract}

$\mathrm{F}$ Tourier transform ion cyclotron resonance (FTICR) methods have become quite popular in mass spectrometry, primarily because of their ability to trap inns for relatively long times. Thus, FTICR instruments have frequently been used to study ion-molecule reactions [1-9]. Physical quantities abstracted from such experiments include relative and absolute reaction rate constants $[2,5]$, proton transfer equilibrium constants [1,4], electron affinities [7], and ionization potentials $[3,6,8,9]$. Because such quantities may strongly depend on ion kinetic energy, development and assessment of schemes to estimate kinetic energies are of great importance.

There has been considerable interest in the kinetic energy of ions produced in FTICR mass spectrometers [10-13], and determinations of these energies are still the subject of much debate. Another class of instruments used for the study of ion-molecule reactions is based on the flow drift tube [14]. One such example is the selected ion flow tube (SIFT) [15]. In the SIFT technique ions are not stored, but reactions are investigated by varying the pressure of the neutral reactant contained in a relatively high pressure $(\sim 0.5$ torr $)$ buffer gas in the flow tube. Discrepancies between rate constants determined by FTICR and SIFT or other flow drift tube variants are frequently observed, and these are often ascribed to the presence of translationally

Address reprint requests to John R. Eyler, Department of Chemistry, University of Florida, Gainesville, FL 32611-2046. excited ions in the FTICR mass spectrometer. There exist at least six cases in which the difference between reported flow tube rate constants and FTICR rate constants has heen reronciled by assigning an "effective" ion temperature of $500-1000 \mathrm{~K}$ to ions in the FTICR instrument $[16,17]$. This argument is based on the fact that conventional FTICR reaction cells typically have potentials higher at the trapping plates than at the center of the cell, as shown in the SIMION [18] plot in Figure 1. Thus ions formed at or near the trapping plates will be translationally excited toward the center of the cell [19] and will initially have velocities characteristic of temperatures above thermal. ${ }^{1}$ However, assignment of ion temperatures in the $500-1000 \mathrm{~K}$ range, in an effort to achieve agreement between FTICR and SIFT data, can minimize consideration of some fundamental aspects of FTICR, such as ion motion and relaxation in the analyzer cell.

Measurement of ion kinetic energy in an FTICR mass spectrometer can be approached in several ways. One technique that has been used successfully is ICR kinetic energy spectroscopy or kinetic energy release $[20,21]$. This method measures the kinetic energy of the products of either exoergic ion-molecule reactions or selected ion photodissociation studies to infer electronic state information. The technique is not applicable for the measurement of near-thermal kinetic ${ }^{1}$ Newer cell designs with screened trapping plates greatly reduce this
effect [19]. 


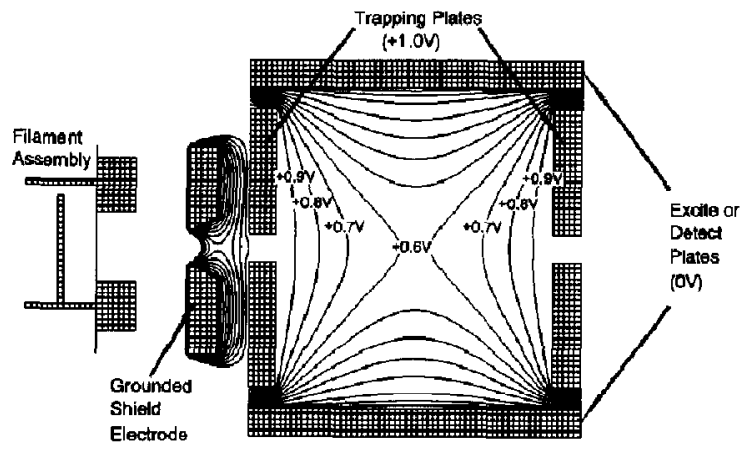

\section{$\mathbf{B} \longrightarrow$}

Figure 1. Equipotential lines in a standard cubic ion cyclotron resonance cell computed by SIMION. T'rapping potential is $1.0 \mathrm{~V}$, the potential applied to the filament assembly is $5.0 \mathrm{~V}$, and other electrodes are at $0 \mathrm{~V}$.

energies due to inefficient ion trapping for cell potentials below $100 \mathrm{meV}$. A second approach for measurement of the kinetic energy of ions in an ICR cell has employed ion time-of-flight determinations [22]. Pulsing the trapping potential to zero for increasingly longer periods of time and measuring the resulting ion intensity decay curve allowed ion kinetic energies to be evaluated. Unfortunately, this technique can be susceptible to stray potentials on the trapping plates or incompletely shielded potentials from the filament assembly.

Several chemical methods for measuring ion kinetic energies were discussed at a recent NATO conference [23]. ${ }^{2}$ The systems proposed for study included proton transfer equilibria, negative ion equilibria, and the rharge exchange reaction of $\mathrm{Ar}^{+}$with $\mathrm{N}_{2}$. The latter reaction seemed most convenient for the present study because of the simplicity of both the reaction and reactants. Furthermore, this reaction has been extensively studied and considerable data exist on its energy dependence. It can be studied with relative ease in FTICR mass spectrometers as well as in quadrupole ion traps (work presented in a companion paper by Basic et al. [24]).

In this article, the $\mathrm{Ar}^{+}+\mathrm{N}_{2}$ reaction rate constant obtained in an FTICR mass spectrometer is compared to determinations in previous work where the reaction was studied as a function of kinetic energy. Although this ion-molecule reactivity approach to estimating ion energies may tend to average time-dependent ion motion and kinetic energies, the comparison does allow a crude estimate of FTICR ion kinetic energy to be made. More important, however, studies of this system permit the relative assessment of ion energies resulting from differing experimental conditions. Parameters may then be adjusted to reduce or minimize ion kinetic energy for situations in which low-energy ions

${ }^{2}$ For a complete summary of the Janel Discussion see ref 23. are critical. In addition, an indication of the average number of collisions necessary to produce varying degrees of thermalization can be obtained by examination of the reaction rate constant over a range of total pressures.

\section{Experimental}

All experiments reported here were carried out on a Nicolet (now Extrel FTMS, Madison, WI) FTMS-1000 system [Nicolet 1280 computer and vacuum controlling electronics, Oxford 3T (Oxford Instruments Limited, Oxford, England) superconducting magnet, vacuum chamber pumped by a $300 \mathrm{~L} / \mathrm{s}$ oil diffusion pump]. The actual pumping speed of this system as used for data presented here was somewhat less than $300 \mathrm{~L} / \mathrm{s}$, because the main gate valve that isolates the vacuum chamber from the pump was partially closed (reproducibly to a $1 / 4$ open position). Operation with a partially closed valve was beneficial because it greatly reduced pressure fluctuations and the system factor (defined below). Typical background pressures were in the low $10^{-9}$ torr region even with the valve partially closed. The basic principles of FTICR and details regarding this instrument can be found elsewhere [25-27].

Ion-molecule reactions are examined in the FTICR instrument by observing the time dependence of the intensity of reactant ions in a constant pressure of reactant gas. Rate constant extraction from the raw data ultimately involves division by the pressure of the neutral reactant; therefore, determination of this pressure is crucial for accurate ion-molecule reaction rate constant measurements. Pressure was monitored by an ionization gauge ${ }^{3}$ mounted approximately $1.5 \mathrm{~m}$ from the ICR cell, external to the magnetic field. The pressure readings taken from the ionization gauge were corrected by two multiplicative factors. The first factor corrected the ionization gauge for sensitivity differences of different gases. This factor was measured by plotting simultaneous ionization gauge and capacitance manometer (MKS Baratron 200 Series, Type $270 A$ x MKS Instruments, Inc., Burlington, MA) pressure readings on a sample of trapped gas. A sensitivity correction factor for each gas used in this work was obtained from the slope of these plots. The second factor corrected the ionization gauge readings for the difference in pressure between the ionization gauge and the ICR cell. This factor is called the system factor, $f_{\text {sys }}$, and is defined by

$$
f_{\text {sys }}=\frac{P_{\text {cell }}}{P_{\text {ion gauge }}}
$$

\footnotetext{
${ }^{3}$ The ion gauge used here cmployed a standard thoria-coated nude ionization gauge filament, model RF-II from Huntington I aboratories, Inc., Mountain View, CA, with a model 274025 Digital Ioniza tion Gauge Controller, Granville-Phillips Company, Boulder, CO.
} 
The system factor was evaluated by performing three separate experiments. The first measurement involved the kinetic energy-independent [28] reaction

$$
\mathrm{CH}_{4}^{+}+\mathrm{CH}_{4} \rightarrow \mathrm{CH}_{5}^{+}+\mathrm{CH}_{3}
$$

This most-studied ion-molecule reaction was used for calibration purposes in the present study. Raw data for this reaction are shown in Figure 2. The pressure dependence of the rate constant for this reaction was also investigated; the results are shown in Figure 3. Also indicated in Figure 3 is the average of numerous previously published values [29]. ${ }^{4}$ The system factor was obtained by dividing the average observed rate constant by the average literature rate constant. A second system factor determination was performed by connecting the capacitance manometer to a hollow stainless stecl tube (i.d. $=10 \mathrm{~mm}$ ) and inserting the tube through the solids probe inlet port into the vacuum chamber so that the open end of the tube was within a few millimeters of the cell. The ratio of the capacitance manometer reading to the sensitivity corrected ionization gauge reading was interpreted as the system factor. The final determination involved placing a second ionization gauge at the location of the ICR cell, in place of the cell, in the absence of a magnetic field. The ratio of the readings of the ion gauge at the cell position to those of the normal ion gauge (both readings independently sensitivity corrected and on a system with the gate valve adjusted to the $1 / 4$ open position) yielded the system factor. All three experiments produced a system factor quite close to $2.0(2.0,2.0$, and 1.9 for the kinetic energy-independent study, the Baratron and hollow solids probe versus the

${ }^{4}$ The rate constant ased is an average of 20 reported values $(1.13 \times$ $\left.10^{-4} \mathrm{~cm}^{3} \mathrm{~s}^{-1}\right)[29]$.

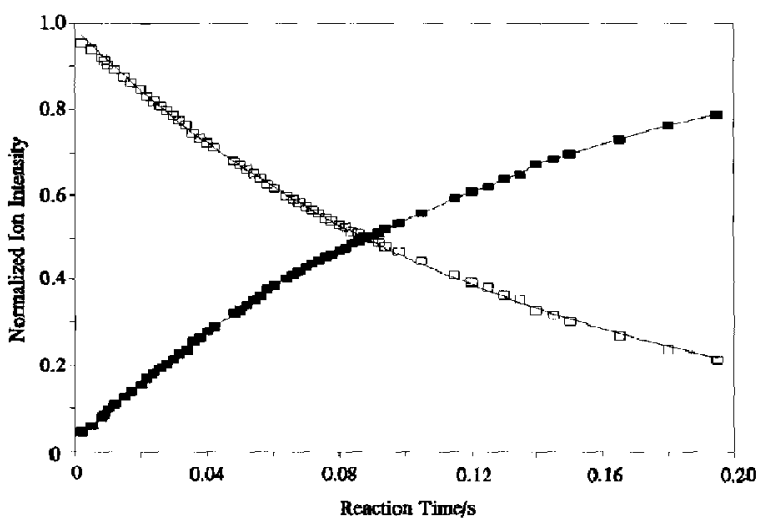

Figure 2. Typical data obtained for the kinetic energyindependent reaction $\mathrm{CH}_{4}^{+}+\mathrm{CH}_{4} \rightarrow \mathrm{CH}_{5}^{+}+\mathrm{CH}_{3}$ used to obtain the system factor, $f_{\text {sys }}$ estimate. Empty rectangles represent the normalized signal due to $\mathrm{CH}_{4}^{+}$ions, filled rectangles that due to $\mathrm{CH}_{5}^{+}$ions. These data were collected at a methane pressure of $2.9 \times 10^{-7}$ torr (corrected).

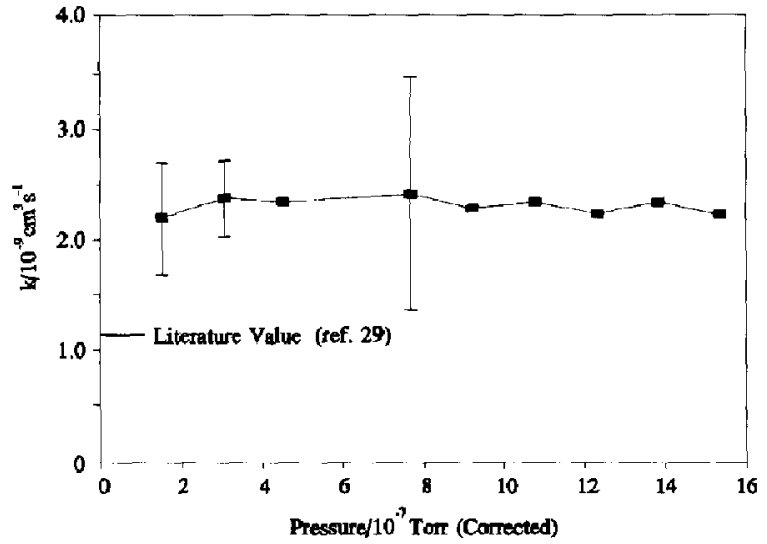

Figure 3. Reaction rate constant as a function of pressure for the $\mathrm{CH}_{4}^{+}+\mathrm{CH}_{4} \rightarrow \mathrm{CH}_{5}^{+}+\mathrm{CH}_{3}$ reaction. Error bars shown are the $95 \%$ confidence limits of the mean for multiple determinations.

ion gauge, and the ion gauge versus ion gauge with no magnetic field, respectively). These data indicate that the pressure at the cell was twice as high as the pressure at the ionization gauge, and a system factor of 2.0 has been applied to all pressure measurements (and thus the rate constants derived by using them) presented in this work.

As mentioned above, the kinetic energy-dependent charge exchange reaction,

$$
\mathrm{Ar}^{+}+\mathrm{N}_{2} \rightarrow \mathrm{N}_{2}^{+}+\mathrm{Ar}
$$

was investigated for the determination of ion energies. For this reaction, ions were formed by electron ionization and then allowed a "relaxation period," usually around $100 \mathrm{~ms}$, during which they underwent approximately 10 ion-molecule collisions, lost excess kinetic energy, and relaxed along the $\mathrm{z}$ (magnetic field) axis to the center of the FTICR cell, where detection efficiency has been shown to be the highest $[30,31]$. This relaxation period precludes the observation of any kinetic energy or electronic energy effects on the reactivity of $\mathrm{Ar}^{+}$ions during the first $100 \mathrm{~ms}$ after ion formation. However, such a relaxation period was necessary to avoid an initial increase in ion intensity due to the collisional relaxation of ions to the center of the cell. As discussed later, only after this period of time could reproducible exponentially decaying $\mathrm{Ar}^{+}$signals, indicative of a pseudo-first-order reaction, be obtained.

A nominal electron energy of $16 \mathrm{~V}$ was used for electron ionization. The typical trapping voltage was $1 \mathrm{~V}$, but effects of the trapping voltage on ion energy were examined over the range $0.5-5 \mathrm{~V}$. 'lhe effect of collisional cooling on ion energy was also investigated by varying the total pressure over the range from $4.0 \times 10^{-7}$ to $2.0 \times 10^{-5}$ torr with the $\mathrm{Ar} / \mathrm{N}_{2}$ pressure ratio varied independently from 10 to 0.20 . All gases were of ultrahigh purity grade and were used as obtained. 
The ion transient response signals consisted in most cases of $16 \mathrm{~K}$ data points, were obtained in the broadband mode, and encompassed frequencies that corresponded to the mass range of 17.3-1000 u (The lower limit was set by the maximum analog-to-digital converter rate possible with our clectronics.) This precluded the direct observation of ions with masses 16 and 17 (i.c., $\mathrm{CH}_{4}^{+}$and $\mathrm{CH}_{5}^{+}$from the kinctic encrgy-independent study); however, increasing the excitation frequency to above $2.667 \mathrm{MHz}$ excited these ions and they could be observed as "reflected peaks" around 17.6 and $18.6 u$ [32]. These ions could also be observed by using the heterodyne detection mode. Ion frequencies were mixed with a carrier frequency of 3.135 $\mathrm{MHz}$. Sum and difference frequencies resulted from this mixing and the selection of the difference frequency by a suitable low-pass filter resulted in frequencies for masses 16 and 17 that were lower than $2.667 \mathrm{MHz}$ and could be observed directly. Both methods yielded the same rate constant for reaction 1 , and consequently the "reflection technique" was more commonly employed due to its simplicity.

For reaction 2, $\mathrm{Ar}^{+}$and $\mathrm{N}_{2}^{+}$ions were formed by electron ionization. The $\mathrm{N}_{2}^{+}$ions formed by the electron beam as well as those produced by reaction 2 must be removed continually by single frequency excitation at the $N_{2}^{+}$cyclotron frequency to prevent the reverse of reaction 2 from taking place (exothermic for $\mathrm{N}_{2}^{+}$formed in excited vibrational levels) [33]. Because only $\mathrm{Ar}^{+}$ions are present in the cell after this ejection (with the exception of a small amount of $\mathrm{H}_{2} \mathrm{O}^{+}$), ion loss must be carefully monitored. Normalization to account for nonreactive $\mathrm{Ar}^{+}$ion loss was not possible; for each pressure and trapping voltage, the electron beam current and/or beam length was adjusted so that little or no $\mathrm{Ar}^{+}$signal loss was seen when no $\mathrm{N}_{2}$ was present in the chamber. Ion energies were extracted from the rate data by comparison with flow drift tube and variable temperature selected ion flow drift tube (VT-SIFDT) results for the kinetic energy dependence of the rate constant of reaction 2 .

\section{Results and Discussion}

$\mathrm{Ar}^{+}$ions produced by electron ionization in the 15$17 \mathrm{eV}$ range should have ${ }^{2} \mathrm{P}_{1 / 2}$ and ${ }^{2} \mathrm{P}_{3 / 2}$ states populated in a statistical $1: 2$ ratio based on the total angular momentum quantum numbers. Hamdan et al. [16] have shown that both states are produced by electron ionization and the reactivity (for charge transfer with $\mathrm{N}_{2}$ ) of the higher energy $\mathrm{J}=1 / 2$ state is approximately three times that of the $\mathrm{J}=3 / 2$ state at collision energies below $0.2 \mathrm{eV}$. However, they also reported that the $\mathrm{J}=1 / 2$ state has a quenching rate constant that is nearly equal to the reaction rate constant. Kinetic modeling of this reaction system without the inclusion of an additional buffer gas was performed by using the following reactions:

$$
\begin{aligned}
\operatorname{Ar}^{+}\left({ }^{2} P_{3 / 2}\right)+N_{2} & \rightarrow N_{2}^{+}+A r \\
\operatorname{Ar}^{+}\left({ }^{2} P_{1 / 2}\right)+M & \rightarrow \operatorname{Ar}^{+}\left({ }^{2} P_{3,2}\right)+M \\
\operatorname{Ar}^{+}\left({ }^{2} P_{1 / 2}\right)+N_{2} & \rightarrow N_{2}^{+}+\operatorname{Ar}
\end{aligned}
$$

The rate constants used [16] werc $\mathrm{k}_{3}=1.1 \times 10^{-11} \mathrm{~cm}^{3}$ $\mathrm{s}^{-1}, \mathrm{k}_{4}=3.2 \times 10^{-11} \mathrm{~cm}^{3} \mathrm{~s}^{-1}$, and $\mathrm{k}_{5}=3.6 \times$ $10^{11} \mathrm{~cm}^{3} \mathrm{~s}^{-1}$. The possibility of spin conversion from the $J=3 / 2$ state to the $J=1 / 2$ state through collisions with neutrals was neglected. The results of the modeling are shown in Figure 4.

This model shows that, while minor deviations from the exponential fit do occur at longer times, the primary effect of the higher energy spin state is an increase in reactivity at short reaction times. The rate constant for the $\mathrm{Ar}^{\prime}\left({ }^{2} \mathrm{P}_{3 / 2}\right)$ reaction is only $3 \%$ lower than that for the total $\mathrm{Ar}^{+}$reaction. As shown in Figure 4, the largest deviation of the total $\mathrm{Ar}^{+}$signal from an exponential fit is observed for reaction times less than $100 \mathrm{~ms}$. This time period corresponds to the relaxation period which was always implemented in our work to allow collisional relaxation of ions to the center of the cell. Because our data collection began after this time period, we did not observe any curvature due to the difference in reactivity of the two spin states when the $\ln \left(\mathrm{Ar}^{+}\right)$signal was plotted as a function of reaction time.

The charge exchange reaction (reaction 2) was used to estimate ion temperatures or kinetic energy, as well as to investigate the effects of various experimental parameters on ion energy. Typical data for reaction 2 are shown in Figure 5. Figure 6 shows the increase in ion signal that was observed when no relaxation delay was implemented. Note that there was no observed growth of $\mathrm{N}_{2}^{+}$, because $\mathrm{N}_{2}^{+}$was continually ejected by

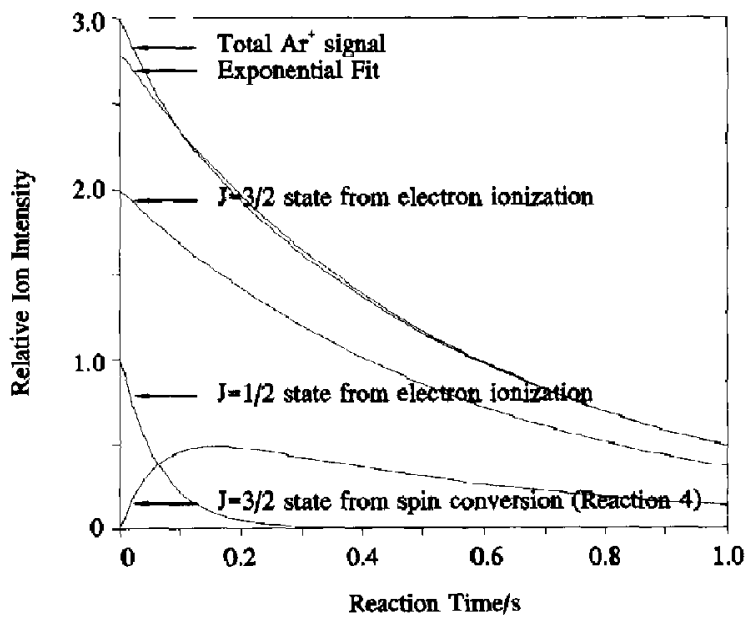

Figure 4. $\mathrm{Ar}^{+}$intensities as a function of time predicted by a model (see text) of the $\mathrm{Ar}^{+}+\mathrm{N}_{2}$ system based on rate constants from ref 16 and pressures of $2 \times 10^{-6}$ tort of each gas. The major contribution of the $\mathrm{J}=1 / 2$ state to $\mathrm{Ar}^{+}$decay is for reaction times less than $100 \mathrm{~ms}$. 


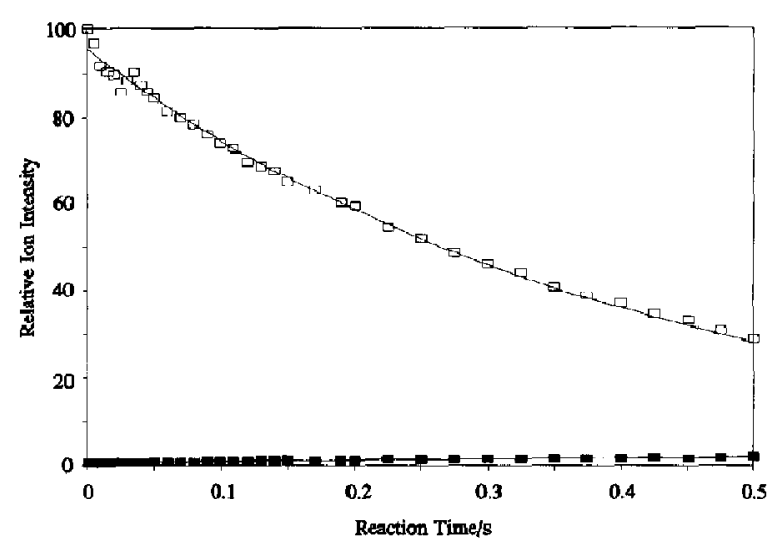

Figure 5. Data for the kinetic energy-dependent reaction $\mathrm{Ar}^{+}+$ $\mathrm{N}_{2} \rightarrow \mathrm{Ar}+\mathrm{N}_{2}^{+}$taken with $100 \mathrm{~ms}$ relaxation delay. These data were obtained with pressures of $2 \times 10^{-6}$ torr of each gas. The filled rectangles are $\mathrm{H}_{2} \mathrm{O}^{+}$and the empty rectangles are $\mathrm{Ar}^{+}$ relative intensities.

a single frequency cyclatron resonance ejection to prevent the possible reverse charge exchange reaction from occurring. Under the ejection conditions used, it can be estimated that the ejected ion struck the ICR cell plate in $100 \mu \mathrm{s}$ after formation. Given the (corrected) pressure of $4.0 \times 10^{-6}$ torr, an estimate of 0.01 collisions during this time can be made (see ref 12 for a similar calculation). A small quantity of $\mathrm{m} / \mathrm{z} 18$ formed with time from the charge transfer reaction between $\mathrm{Ar}^{+}$and trace quantities of $\mathrm{H}_{2} \mathrm{O}$.

The results of a pressure dependence study of the rate constant for reaction 2 are shown in Figure 7 . In this study, the lolal pressure was varied over the range from $4.0 \times 10^{-7}$ to $2.0 \times 10^{-5}$ torr with various $\mathrm{Ar} / \mathrm{N}_{2}$ pressure ratios ranging from 10-0.20. Error limits indicate the $95 \%$ confidence limits of the mean of multiple determinations ( $\mathrm{n}=4$ to 32 ) at a constant total pres-

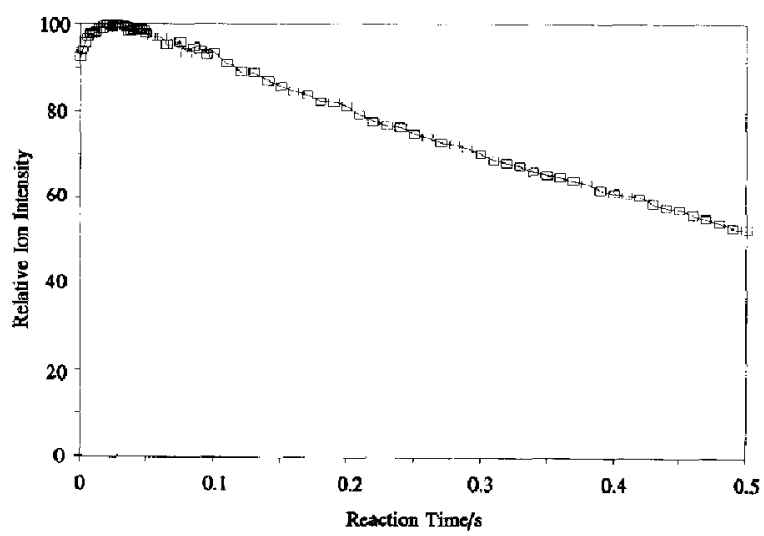

Figure 6. Data for the kinetic energy-dependent reaction $\mathrm{Ar}^{+}+$ $\mathrm{N}_{2} \rightarrow \mathrm{Ar}+\mathrm{N}_{2}^{+}$taken without the standard $100 \mathrm{~ms}$ relaxation delay. These data were obtained with pressures of $2 \times 10^{-6}$ torr of each gas. The increase in intensity at short reaction times is due to the relaxation of the ion cloud toward the center of the cell where detection efficiency is the highest.

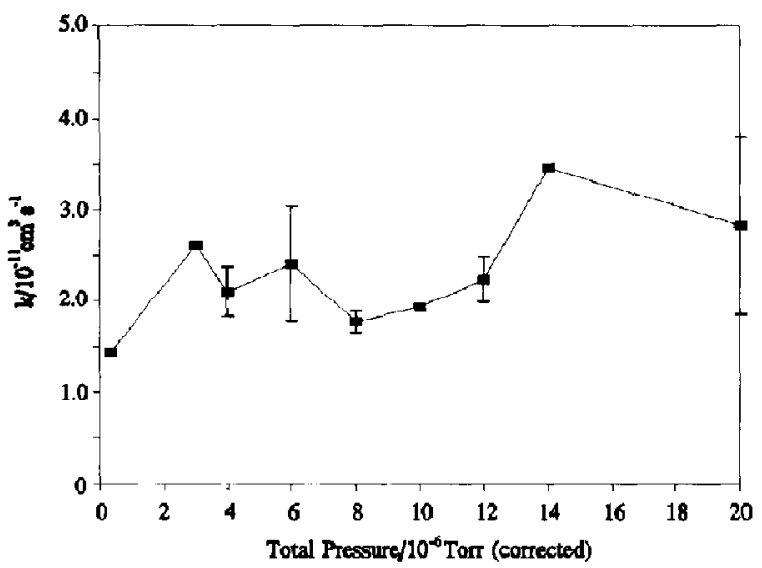

Figure 7. Rate constant as a function of pressure for the kinetic energy-dependent $\mathrm{Ar}^{+}+\mathrm{N}_{2}$ reaction. The total pressure is plotted on the abscissa. The total pressure was varied over the range from $4.0 \times 10^{-7}$ torr to $2.0 \times 10^{-5}$ torr, with the ratio of $\mathrm{Ar} / \mathrm{N}_{2}$ independently ranging from $10-0.20$. No dependence of the rate constant on total pressure was observed within the $95 \%$ confidence limits of the mean for multiple determinations shown.

sure. The larger fluctuations in these data are probably due to the relatively slow rate of the reaction, which requires operation in a pressure region somewhat high by FTICR standards. Clearly, there is no significant effect of total pressure on the rate constant. Therefore, one may conclude that the $100 \mathrm{~ms}$ delay (discussed above) used to allow ions to relax to the center of the cell is also sufficient to allow the thermalization of ions formed with higher than thermal kinetic energies. Kinetics data for this reaction could not be collected without the relaxation delay because of the observed effect on the ion intensity illustrated in Figure 6. However, because the total pressure (corrected both for gas sensitivities as well as for a system factor of 2.0 ) was usually $4.0 \times 10^{-6}$ torr or higher, one many use a Langevin [34] cross section to estimate that, with an average of as few as 13 collisions, $\mathrm{Ar}^{+}$ions were collisionally cooled to a kinetic energy that could not be reduced by additional collisions.

Because the trapping voltage is believed to be a major cause of translationally excited ions [35], its effect on the charge exchange reaction rate constant was also examined. The results of this study are shown in Figure 8. The data were obtained at constant argon and nitrogen pressures. As the trapping voltage was varied, the electron ionizing time and/or current were systematically adjusted to produce approximately the same signal intensities (and presumably approximately the same number of ions) at each trapping voltage. Data are shown for trapping voltages between 0.3 and $5 \mathrm{~V}$. Error limits indicate $95 \%$ confidence limits of the mean for multiple determinations $(\mathrm{n}=3$ to 8 ) at a single trapping voltage. The results show no dependence of the rate constant on the trapping voltage. Thus the results of both the pressurc and trapping 


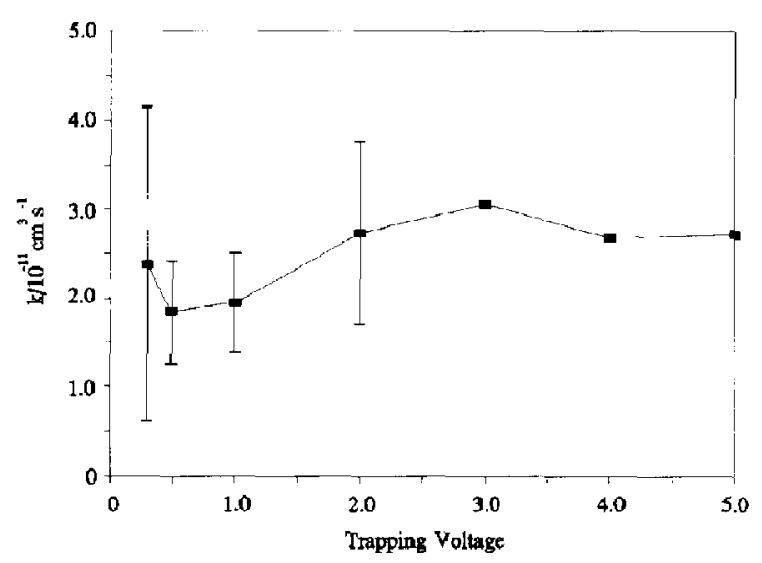

Figure 8. Rate constant as a function of trapping voltage for the kinetic energy-dependent reaction $A r^{\prime}+N_{2}$. All determinations were performed with $6 \times 10^{-6}$ torr of argon and $6 \times 10^{6}$ torr of nitrugen. Shown are the $95 \%$ confidence limits of the mean of multiple determinations.

voltage studies indicate that even though ions may be formed with considerable excess kinetic energy, within the first $100 \mathrm{~ms}$ after formation they rapidly undergo collisional relaxation to the center of the cell.

$\Lambda_{n}$ "effective" ion temperature may be extracted from this work by averaging all the rate constant determination results and comparing them to the flow drift tube work of Dotan and Lindinger [36]. Our average value for the charge exchange reaction coefficient is $(2.4 \pm 0.2) \times 10^{11} \mathrm{~cm}^{3} \mathrm{~s}^{1}$ in good agreement with $(2.2 \pm 0.2) \times 10^{-11} \mathrm{~cm}^{3} \mathrm{~s}^{-1}$ determined in earlier ICR studies [37]\}. By comparison to the flow drift tube data (Figure 3 of ref 36 ), one obtains a center of mass kinetic energy, K.E..$_{\mathrm{cm}}$, of $0.065 \pm 0.010 \mathrm{eV}$.

K.E. ${ }_{\mathrm{cm}}$ is defined by

$$
\mathrm{K} . \mathrm{E}_{{ }_{\mathrm{cm}}}=1 / 2 \mu \mathrm{v}_{\mathrm{r}}^{2}
$$

where $\mu$ is the reduced mass of the colliding pair and $\mathrm{v}_{\mathrm{T}}^{2}$ is the square of the relative velocity. One can then solve for $v_{r}^{2}$ because $\mu$ is easily obtained from the ion and neutral masses. The square of the relative velocity is related to ion and neutral temperatures by [38]

$$
v_{r}^{2}=3 k\left(T_{n} / m_{n}+T_{i} / m_{i}\right)
$$

if one assumes that the colliding neutrals and ions have separate Maxwell-Boltzmann distributions of velocities about temperatures $T_{n}$ and $T_{i}$, respectively. ${ }^{5}$ The temperature of the ICR cell as measured with a resistive temperature device was $375 \mathrm{~K}$. By using this for $T_{n}$, which is the temperature of $N_{2}$ molecules, one nbtains a temperature of $690 \pm 190 \mathrm{~K}$ for $T_{j}$, the temperature of the $\mathrm{Ar}^{+}$ions. This result seems suspiciously high.

Bowers and co-workers [39] calculated the tempera-

${ }^{5}$ This result, derived by us in a manner similar to that of Kennard [38(a)] yiclds the same result als the equations presended by MiFarland $[38(b)]$, ture for ions generated along the trapping potential surface by approximating this surface with

$$
\mathrm{v}_{\mathrm{z}}=\left(\mathrm{V}_{\mathrm{1}} / 2\right)\left(\mathrm{z}^{2}+1\right)
$$

where $\mathrm{z}$ is the distance along the $\mathrm{z}$ (magnetic field) axis with the origin at the center of the cell, and $V_{T}$ is the applied trapping voltage. Assuming a thermal distribution for the neutral species and integrating over all z points of ion formation, their group estimated the velocities of ions to be only $50 \%$ greater than thermal for a $1 \mathrm{~V}$ trapping voltage in the absence of any thermalizing collisions. It is doubtful that the temperature of the $\mathrm{Ar}^{+}$ions would be almost twice the neutral temperature after 10 collisions with argon atoms or nitrogen molecules.

Alternately, one may compare the obtained rate constant to the more recent VT-SIFDT work of Viggiano et al. [40]. They investigated the kinetic energy dependence of the $\mathrm{Ar}^{+}+\mathrm{N}_{2}$ reaction by varying the drift voltage at constant temperature as well as the temperature at constant drift voltage. While some uncertaintics remain in their interpretation, the results showed that, at lower K.E. . $\mathrm{mt}$ values, the effect of varying the temperature on the rate constant was not equivalent to the effect produced by altering the drift voltage. They concluded that increased temperatures probably led to an increase in the rotational energy of $\mathrm{N}_{2}$. When plotted as a function of total energy, their rate constant data showed that, with a rotational contribution of $\mathrm{kT}$, all points (Figure 3 of ref 40 ) fell on the same curve. Comparing the present FTICR data with that from the VT-SIFDT instrument indicates that the total energy for the reaction in the ICR cell is in the range 0.080-0.10 $\mathrm{eV}$, which is defined as the average center of mass kinetic energy plus the average rotational energy. Again by using $375 \mathrm{~K}$ for $T_{n}$ and subtracting $k T_{n}$ (the rotational energy of $\mathrm{N}_{2}$ ) from the total energy range given above, one obtains $0.048-0.068 \mathrm{eV}$ for $K . \mathrm{E}_{\mathrm{cm}}$. These kinetic energies correspond to an "effective" temperature (by using equation 3) of $545 \pm 190 \mathrm{~K}$ for the $\mathrm{Ar}^{+}$ions. Although still somewhat high, this range does encompass the thermal value.

\section{Conclusions}

Measurements of the kinetic energies of ions produced in an FTICR instrument are crucial to the interpretation of data obtained from ion-molecule reactions. Several conclusions can be obtained from the present study. First, electronic states of $\Lambda \mathbf{r}^{+}$of energy equal to or higher than that of ${ }^{2} \mathrm{P}_{1 / 2}$, if present, react with the same rate constant as ${ }^{2} \mathrm{P}_{3 / 2}$ or are rapidly relaxed. Second, no additional collisional cooling was observed after the $100 \mathrm{~ms}$ relaxation period, indicating that by that time, ions have been translationally cooled to a level which is unaffected by additional collisions. The value of this kinetic energy plateau is still not well defined; however, based on recent VT-SIFDT measurements, it is believed to be only slightly above thermal. 
The initial growth of ion intensity, which was avoided in our work by including the relaxation period, could itself serve as a "thermometer," indicating that ions have reached thermalization when the ion intensity maximizes. Because the detection efficiency has been shown to be position-dependent, and the average position in the trapping well is kinetic energy-dependent, one can conclude that the detection efficiency is itself dependent on the kinetic energy, with a maximum efficiency observed when the kinetic energy is at a minimum. Finally, the pressure-dependence study indicates that the $\mathrm{Ar}^{+}$ions are collisionally relaxed with as few as 13 collisions.

The assignment of temperatures to trapped ions depends heavily on the assumption that the ions have a Maxwell-Boltzmann distribution of velocities. Current experiments being performed in this laboratory have allowed some of the previously mentioned problems associated with the time-of-flight kinetic energy measurements in an FTICR mass spectrometer to be overcome. Although not yet complete, experiments utilizing this modified time-of-flight technique support the assumption of a Maxwell-Boltzmann distribution of velocities for the ions.

\section{Acknowledgments}

This work was supported in part by the Office of Naval Research. We thank Ms. Cecilia Basic, Dr. Kathryn Williams, and Prof. Richard Yost for numerous helpful suggestions.

\section{References}

1. Devlin, J. L. III; Wolf, J. F; Taft, R.; Hehre, W. J. J. Am. Chem. Soc. 1976, 98, 1990.

2. Anicich, V. G.; Kim, J. K.; Huntress, W. T. Int. /. Mass Spectrom. Ion Phys. 1977, 25, 433.

3. Lias, S. G.; Ausloos, P. I. Am. Chem. Soc. 1978, 100, 6027.

4. Taft, R. W. In Kinetics of Ion-Molecule Reactions; Ausloos, P., Ed.; Plenum: New York, 1979; p 271.

5. McElvany, S. W.; Dunlap, B. I.; OKeefe, A. I, Chem. Phys. 1987, 86, 715 .

6. Bach, S. B. H.; Eyler, J. R. J, Chem. Phys. 1990, 92, 358.

7. Sharpe, P.; Eyler, J. R.; Richardson, D. E. Inorg. Chem. 1990, 29, 2779 .

8. Zimmerman, J. A.; Bach, S. B. H.; Watson, C. H.; Eyler, J. R. J. Phys. Chem. 1991, 95, 98.

9. Zimmerman, J. A.; Eyler, J. R.; Bach, S. B. H.; McElvany, S. W. J. Chem. Phys. 1991, 94, 3556.

10. Hanson, C, D.; Kerley, E. L.; Castro, M. E.; Russell, D. H. Anal. Chem. 1989, 61, 2040-2046.

11. McMahon, T. B.; Willett, G. D. Int. J. Mass Spectrom. Ion Proc. 1990, 101, 225-231.

12. Katritzky, A. R.; Watson, C. H.; Dega-Szafran, Z.; Eyler, J. R. J. Am. Chem. Soc. 1990, 112, 2471.

13. Grosshans, P. B.; Shields, P.; Marshall, A. G. J. Am. Chem. Soc. 1990, 112, 1275-1277.
14. McDaniel, E. W.; Martin, D. W.; Barnes, W. S. Rev. Sci. Instrum. 1962, 33, 2.

15. Adams, N. G.; Smith, D. Int. J. Mass Spectrom. Ion Phys. 1976, 21, 349-359.

16. Hamdan, M.; Birkinshaw, K.; Twiddy, N. D. Int. I. Mass Spectrom. Ion Processes 1984, 57, 225-231.

17. Henchman, M. In Structure / Reactivity and Thermochemistry of lons; Ausloos, P,; Lias, S. G., Eds.; Plenum: New York, 1987; $\mathrm{p} 376$.

18. Dahl, D. A.; Delmore, J. E. SIMION PC/PS2 Version 4.0, EGG-CS-7233 Rev. 2, April 1988; Idaho National Engineering Laboratury, EG \& G Idaho Inc.: Idaho Falls, ID.

19. Wang, M.: Marshall, A.G. Anal. Chem. 1989, 61, 1288-1293.

20. Mauclaire, G.; Derai, R,; Fenistein, S.; Marx, R. 1. Chem. Phys. 1979, 70, 4023.

21. Rincon, M. E.; Pearson, J.; Bowers, M. T. J. Phys. Chem. 1988, 92, 4290-4292.

22. Dunbar, R. C.; Wedale, G. H. I. Phys. Chem. 1988, 92, 5706.

23. Ausloos, P.; Lias, S. G., Eds.; Structure / Reactivity and Thermochemistry of lons; Plenum: New York, 1987; pp 367-380.

24. Basic, C.; Eyler, J. R.; Yost, R. A. I. Am. Soc. Mass Spectrom. 1992, 3, 716-726.

25. Baykut, G.; Eyler, J. R. Trends Anal. Chem. 1986, 5, 44.

26. Buchanan, M. V.; Comisarow, M. B. In Fourier Trunsform Mass Spectrometry: Evolution, Inmozation $r$ and Applications; ACS Symp. Series 359; Buchanan, M. V., Ed.; American Chemical Socicty: Washington, DC, 1987; pp 1-20.

27. Marshall, A.G.; Grosshans, P. B. Anal. Chem. 1991, 63, 215A.

28. Meot-ner, M. In Gas Phase Ion Chemistry Vol. 2; Bowers, M. T., Ed.; Academic Press: New York, 1979; pp 198-268.

29. Ikezoe, Y.; Matsuoka, S.; Takebe. M.; Viggiano, A. A. Cas Phase Reaction Rate Constants Through 1986; Maruzen Co.: Tokyo, Japan, 1987.

30. Rempel, D. I.; Huang, S. K.; Gross, M. L. Int. J. Mass Spectrom. Ion Proc. 1986, 70, 163-184.

31. van der Hart, W. J; van de Guchte, W. J. Int. J. Mass Spectrom. Ion Proc. 1988, 17-31.

32. Cody, R. B.; Kinsinger, J. A.; Goodman, S. D. Anal. Chem. 1987, 59. 2567-2569.

33. Liao, C. L.; Shao, R.; Xu, G. D.; Flesch, Y. G.; Ng, C. X. I Chem. Phys. 1986, 85, 3874.

34. Langevin, P. M. Ann. Chim. Phys. 1905, 5, 245. Translated in: McDaniel, E. W. Collision Phenomena in Ionized Gases, Wiley: New York, 1964; Appendix II.

35. Bartmess, J. E. In Structure / Reactivity and Thermochemistry of Ions; Ausloos, P.; Lias, S. G., Eds.; Plenum: New York, 1987; p 368.

36. Dotan, I.; Lindinger, W. J. Chern. Phys. 1982, 76, 4972.

37. Laudenslager, J. B.; Huntress, W. T. Jr.; Bowers, M. T. I. Chem. Phys. 1974, 61, 4600.

38. (a) Kennard, E. H. Kinetic Theory of Gases, With an Introduction to Statistical Mechanics 1st ed.; MeGraw-Hill: New York, 1938; pp 105-109. (b) McFarland, M.; Albritton, D. L.; Fehsenfeld, F. C.; Ferguson, E. E.; Schmeltekopf, A. L. J. Chem. Phys. $1973,59,6620$.

39. Chesnawich, W. J.; Su, T.; Bowers, M. T. J. Chem. Phys, 1976, 65,990 .

40. Viggiano, A. A.; Van Doren, J. M.; Morris, R. A.; Paulson, J. F. J. Chem. Phys. 1990, 93, 4761. 